\title{
Guillain-Barré and Alpha-gal Syndromes: Saccharides-induced Immune Responses
}

\author{
José de la Fuente ${ }^{*}, 1,2$, Iván Pacheco ${ }^{1}$, Marinela Contreras ${ }^{1}$, Lourdes Mateos-Hernández ${ }^{1,3}$, \\ Margarita Villar ${ }^{1}$ and Alejandro Cabezas-Cruz ${ }^{3}$
}

${ }^{1}$ SaBio, Instituto de Investigación en Recursos Cinegéticos IREC-CSIC-UCLM-JCCM, Ronda de Toledo s/n, 13005 Ciudad Real, Spain; ${ }^{2}$ Department of Veterinary Pathobiology, Center for Veterinary Health Sciences, Oklahoma State University, Stillwater, OK 74078, USA; ${ }^{3}$ UMR BIPAR, INRA, ANSES, Ecole Nationale Vétérinaire d'Alfort, Université Paris-Est, Maisons-Alfort, 94700, France

\begin{abstract}
The molecular interactions between hosts, vectors and pathogens drive the etiology of infectious diseases. At first sight, the Guillain-Barré and Alpha-Gal syndromes have quite different etiologies but, as proposed here, a closer look into the immune response to galactose-containing oligosaccharide structures that characterizes these two diseases reveals striking commonalities. In this Opinion paper, we address the main molecular drivers of two apparently unrelated diseases, and how the characterization of the immune response and immunological tolerance would advance the control and prevention of these diseases.
\end{abstract}

Guillain-Barré syndrome (GBS) is an immune-mediated peripheral neuropathy, with an annual incidence of approximately 1-2 cases per 100,000 persons. $^{1-3}$ The most common symptom of GBS is a rapidly evolving, ascending weakness, with mild sensory loss and hyporeflexia or areflexia progressing to a nadir over up to 4 weeks. ${ }^{2,3}$ GBS is considered to be an autoimmune disease with involvement of both cellular and humoral immune responses, ${ }^{2}$ but about a quarter of the patients with GBS have suffered a recent bacterial or viral infection, and axonal forms of the disease are especially common in these patients. ${ }^{2,4-9}$ Pathogens such as Campylobacter jejuni, Haemophilus bacteria and Cytomegalovirus have been shown to have oligosaccharide structures [Gal beta 1-3 GalNAc beta 1-4 (NeuAc alpha 2-3) Gal beta] in their lipopolysaccharide coat responsible for the molecular mimicry that triggers GBS. ${ }^{2,5,7,10-13}$ In addition, different types of viral diseases, such as hepatitis caused by hepatitis $\mathrm{C}$ virus, acquired immune deficiency syndrome caused by the human immunodeficiency virus and disease caused by the mosquito-borne Zika virus, have been related to GBS. ${ }^{8,9}$ Additionally, rare cases of GBS have been reported after treatment with inactivated influenza vaccine. ${ }^{14}$ Recent results have shown that infection with these pathogens leads to anti-GM1 pen-

Keywords: Immunology; Vaccine; Tick; Infectious disease; Galactose; Allergy; Alpha gal.

Abbreviations: $\alpha$-Gal, Gal $\alpha 1-3$ Gal $\beta 1-(3) 4 G 1 c N A c-R ; A G S$, alpha-Gal syndrome; GBS, Guillain-Barré syndrome.

Received: October 27, 2019; Revised: November 05, 2019; Accepted: November 06 , 2019

*Correspondence to: José de la Fuente, Instituto de Investigación en Recursos Cinegéticos IREC-CSIC-UCLM-JCCM, Ronda de Toledo s/n, 13005 Ciudad Real, Spain. E-mail: jose_delafuente@yahoo.com

How to cite this article: de la Fuente J, Pacheco I, Contreras M, Mateos-Hernández L, Villar M, Cabezas-Cruz A. Guillain-Barré and Alpha-gal Syndromes: Saccharidesinduced Immune Responses. Exploratory Research and Hypothesis in Medicine 2019;4(4):87-89. doi: 10.14218/ERHM.2019.00027. tasaccharide beta-Gal-(1-3)-beta-GalNAc-(1-4)-[alpha-Neu5Ac(2-3)]-beta-Gal-(1-4)-beta-Glc antibody production, which crossreacts with gangliosides and other glycolipids, leading to myelin destruction by complement activation or by antibodies targeting macrophages via the Fc receptor and leading to both demyelination and nerve conduction failure. , $^{2,15}$

Alpha-Gal syndrome (AGS) is a tick-induced allergy triggered by IgE antibody response against the carbohydrate Gal $\alpha 1-$ $3 \mathrm{Gal} \beta 1-(3) 4 \mathrm{GlcNAc}-\mathrm{R}(\alpha-\mathrm{Gal})$, which is present in glycoproteins from tick saliva and tissues of noncatarrhine mammals. ${ }^{16,17}$ AGS is characterized by delayed anaphylaxis to red meat consumption and certain drugs, such as cetuximab, and immediate anaphylaxis to tick bites, and is becoming a global problem with increasing prevalence in all continents and with the involvement of several tick species. ${ }^{16-20}$ Humans do not produce the carbohydrate $\alpha-G a l$ (Gal $\alpha$ 1-3Gal $\beta$ 1-(3)4GlcNAc-R), ${ }^{21}$ and the not yet fully understood immune response induced by tick bites that includes anti- $\alpha$-Gal IgE antibodies break the oral tolerance to food allergens, resulting in a gut-related but not lung-related allergy. ${ }^{16,20}$ The GGTA1 gene encoding for the $\alpha 1,3$-galactosyltransferase enzyme that synthetizes $\alpha$-Gal in mammals was inactivated in humans, apes and Old World monkeys approximately 28 million years ago. ${ }^{21}$ This resulted in an almost unique capacity of these animals to produce high levels of anti- $\alpha$-Gal antibodies. Several pathogens, such as Leishmania, Trypanosoma, Plasmodium and Mycobacterium, have been found to produce $\alpha$-Gal on their surface, and infection with some of these pathogens induces an anti$\alpha-$ Gal response. ${ }^{22,23}$ Anti- $\alpha-G a l$ antibodies can also be produced in response to bacterial microbiota, ${ }^{21}$ and they constitute the most abundant antibody in humans, representing about $1 \%$ of total immunoglobulins. ${ }^{21}$

Anti- $\alpha-$ Gal IgG and IgM antibodies induced by bacterial microbiota were shown to control malaria transmission by complement-mediated lysis. ${ }^{22}$ The proposed mechanisms triggering AGS 

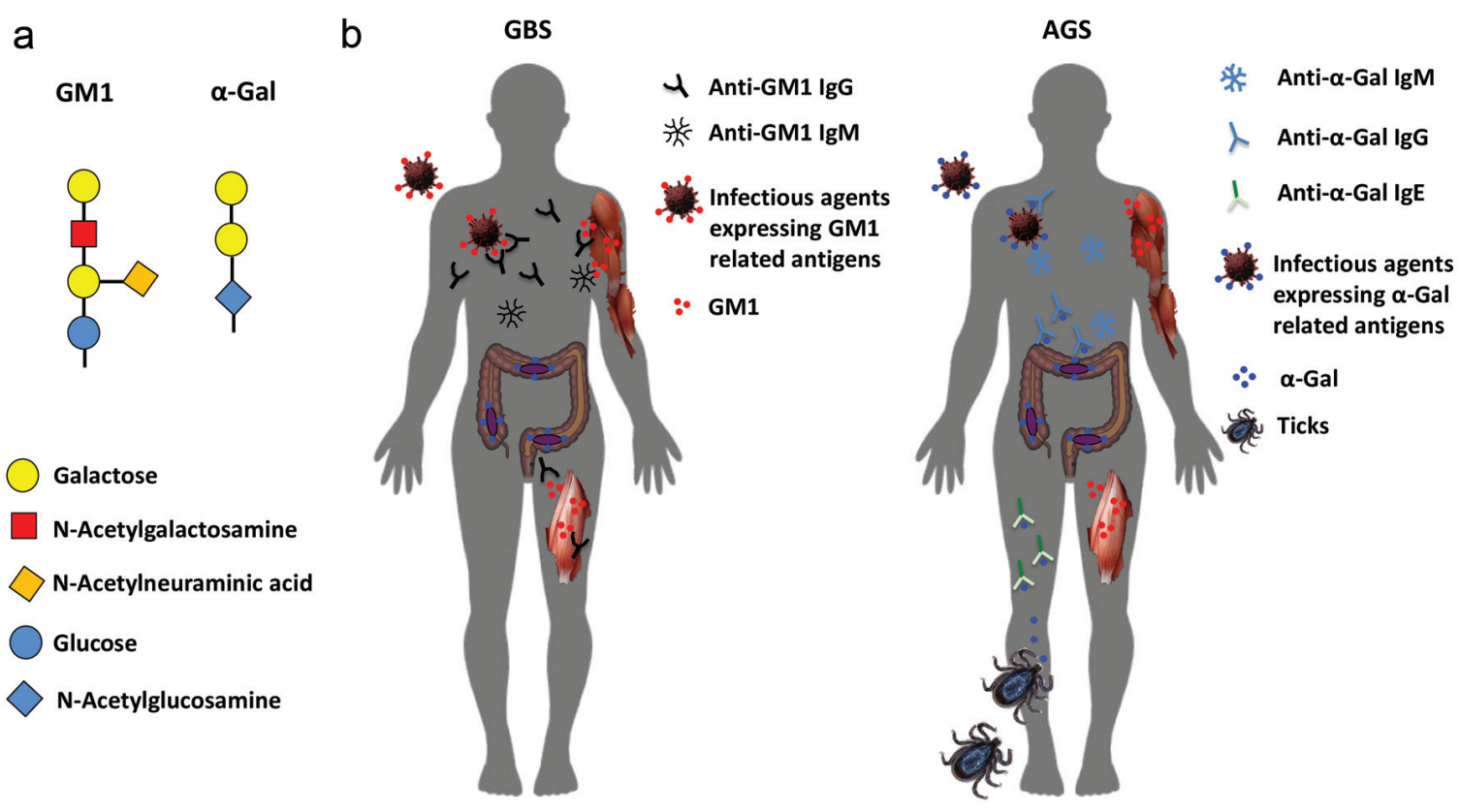

Fig. 1. Immunological similarities between GBS and AGS. (a) Both GBS and AGS are associated to galactose-containing antigens (GM1 and $\alpha$-Gal), in which galactose plays an important role as an antigenic determinant. The chemical structures of GM1 and $\alpha$-Gal are shown. (b) Interplay between infectious agents producing GM1 or $\alpha$-Gal-related antigens and GM1 present in human tissues and $\alpha$-Gal molecules present on the bacterial microbiota. In case of AGS, the $\alpha-G a l$ is found in human gut and associated to microbiota bacteria and food (i.e. red meat). Immune tolerance is lost in both diseases. In GBS, the presence of GM1 on pathogens break the tolerance against this molecule produced in myelinated axons that are associated to motor and sensory nerves. In AGS, pathogens and microbiota induce high levels of anti- $\alpha$-Gal IgM and IgG but after tick bites, anti- $\alpha$-Gal IgE is produced. This process breaks the oral tolerance to food antigens containing $\alpha-G a l$ and results in anaphylactic reaction to red meat. $\alpha-G a l$, Gal $\alpha 1-3 G a l \beta 1-(3) 4 G I c N A c-R ; A G S$, alpha-Gal syndrome; GBS, Guillain-Barré syndrome.

involve Toll-like receptor-mediated responses in both Th1 and Th2 cells, with a role for basophils in this process. ${ }^{16}$ Therefore, GGTA1 gene inactivation might have occurred in response to the selection pressure exerted by pathogens detrimental to primates that produce $\alpha-G a l .{ }^{21}$ Consequently, the capacity of the human immune system to respond to pathogens producing $\alpha$-Gal evolved with the tradeoff of AGS. ${ }^{17,24}$

These results suggested that both GBS and AGS are related to infectious diseases and driven by immune response to galactosecontaining oligosaccharide structures. Humans produce GM1 and the anti-GM1 antibodies induced by pathogen infection break the tolerance to the self-antigen GM1, leading to myelin destruction and GBS. However, humans do not produce $\alpha-\mathrm{Gal}$ and anti- $\alpha-G a l \operatorname{IgE}$ antibodies induced by tick bites result in anaphylactic reaction to the consumption of red meat containing this carbohydrate and leading to the AGS. Interestingly, both diseases overcome the immune tolerance 'easily', a mechanism otherwise known to be quite robust for other antigens, such as cancer-related antigens. ${ }^{25}$ However, differences between the two diseases are also important to consider for the development of proper interventions. ${ }^{26}$

The carbohydrate epitopes involved in GBS are very complex, including a range of gangliosides, such as GM2, GM1, GM1b, GD1a, GalNAc-Gd1a and GQ1b, that beside galactose involve other monosaccharides, including NeuNAc (5-N-acetylneuraminic acid) and GalNAc (2-N-acetyl-galactosamine). The NeuNAc is found in most epitopes of GBS, playing the most important role in the immunochemistry of GBS carbohydrate epitopes. However, the galactosyl oligosaccharide residue plays an essential role in AGS. Pathomechanistically, GBS is the result of the body's adap- tive immune response to foreign antigens, which have structures similar to human gangliosides that generate antibodies accidentally recognizing human gangliosides and resulting in autoimmune reactions. On the other hand, AGS is an allergic reaction triggered by tick bites and after eating red meat containing the $\alpha$-Gal trisaccharide, which is a hyper-reaction of human immune systems to foreign antigens. ${ }^{16}$

What we can learn from these findings? Besides differences in the carbohydrate epitopes playing the main role in GBS and AGS and other pathomechanistic differences, the immunological basis of GBS and AGS have some similarities (Fig. 1). Trying to understand how immunity is regulated in response to galactosecontaining oligosaccharides and other carbohydrate structures produced by pathogens and ticks that result in GBS or AGS is essential to prevent these diseases. ${ }^{15-17}$ Recent results from our group showed that application of the latest postgenomic or omics technologies would facilitate the characterization of the immune response in both GBS and AGS, with the possible identification of target molecules for diagnostics, treatment and prevention of these diseases. ${ }^{27-30}$

In summary, deciphering the immune-mediated mechanisms involved in GBS and AGS would lead to new diagnostic, treatment and prevention/control interventions for these diseases, and have possible implications for the control of major infectious diseases. ${ }^{31}$

\section{Acknowledgments}

We thank the members of our laboratories and collaborators for fruitful discussions. This study was funded by the Consejería de 
Educación, Cultura y Deportes, JCCM, Spain, project CCM17PIC-036 (SBPLY/17/180501/000185). M.V. was supported by the University of Castilla La Mancha, Spain.

\section{Conflict of interest}

This research was conducted in the absence of any commercial or financial relationships that could be construed as a potential conflict of interest.

\section{Author contributions}

Study conception and design (JF, ACC); acquisition of data (IP, $\mathrm{MC}, \mathrm{LMH}, \mathrm{MV}, \mathrm{ACC}, \mathrm{JF})$; analysis and interpretation of data (JF, ACC, MV); drafting of the manuscript (JF, MV); critical revision of the manuscript for important intellectual content (JF, ACC, MV); administrative, technical, or material support, and study supervision (JF, MV).

\section{References}

[1] Guillain G, Barré JA, Strohl A. Sur un syndrome de radiculonévrite avec hyperalbuminose due liquide céphalo-rachidien sans réaction cellulaire. Remarques sur les caractéres cliniques et graphiques des réflexes tendineux. Bull Soc Méd Hôp Paris 1916;40:1462-1470.

[2] Van den Berg B, Walgaard C, Drenthen J, Fokke C, Jacobs BC, van Doorn PA. Guillain-Barré syndrome: pathogenesis, diagnosis, treatment and prognosis. Nat Rev Neurol 2014;10:469-482. doi:10.1038/ nrneurol.2014.121.

[3] Hanewinckel R, Ikram MA, Van Doorn PA. Peripheral neuropathies. Handb Clin Neurol 2016;138:263-282. doi:10.1016/B978-0-12802973-2.00015-X.

[4] KuwabaraS. Guillain-Barré syndrome: epidemiology, pathophysiology and management. Drugs 2004;64:597-610. doi:10.2165/00003495200464060-00003.

[5] Ang CW, Jacobs BC, Laman JD. The Guillain-Barré syndrome: a true case of molecular mimicry. Trends Immunol 2004;25:61-66. doi:10.1016/j.it.2003.12.004.

[6] Estanislao LB, Morgello S, Simpson DM. Peripheral neuropathies associated with HIV and hepatitis C co-infection: a review. AIDS 2005;19(Suppl 3):S135-S139. doi:10.1097/01.aids.0000192082.41561.49.

[7] Kaida K, Ariga T, Yu RK. Antiganglioside antibodies and their pathophysiological effects on Guillain-Barré syndrome and related disorders - a review. Glycobiology 2009;19:676-692. doi:10.1093/glycob/ cwp027.

[8] Rosinska J, Lukasik M, Kozubski W. Neuropathies in the course of primary hepatotropic virus infections. Neurol Neurochir Pol 2012;46:263270. doi:10.5114/ninp.2012.28916.

[9] Nugent EK, Nugent AK, Nugent R, Nugent K. Zika virus: Epidemiology, pathogenesis and human disease. Am J Med Sci 2017;353:466-473. doi:10.1016/j.amjms.2016.12.018.

[10] Yuki N, Taki T, Inagaki F, Kasama T, Takahashi M, Saito K, et al. A bacterium lipopolysaccharide that elicits Guillain-Barré syndrome has a GM1 ganglioside-like structure. J Exp Med 1993;178:1771-1775. doi:10.1084/jem.178.5.1771.

[11] Sawai S, Satoh M, Mori M, Misawa S, Sogawa K, Kazami T, et al. Moesin is a possible target molecule for cytomegalovirus-related Guillain-Barré syndrome. Neurology 2014;83:113-117. doi:10.1212/ WNL.0000000000000566.

[12] Loshaj-Shala A, Regazzoni L, Daci A, Orioli M, Brezovska K, Panovska $\mathrm{AP}$, et al. Guillain Barré syndrome (GBS): new insights in the molecular mimicry between $C$. jejuni and human peripheral nerve (HPN) proteins. J Neuroimmunol 2015;289:168-176. doi:10.1016/j.jneuroim.2015.11.005.
[13] Anaya JM, Ramirez-Santana C, Salgado-Castaneda I, Chang C, Ansari A, Gershwin ME. Zika virus and neurologic autoimmunity: the putative role of gangliosides. BMC Med 2016;14:49. doi:10.1186/s12916016-0601-y.

[14] Miller ER, Moro PL, Cano M, Shimabukuro TT. Deaths following vaccination: What does the evidence show? Vaccine 2015;33:3288-3292. doi:10.1016/j.vaccine.2015.05.023.

[15] Townson K, Boffey J, Nicholl D, Veitch J, Bundle D, Zhang P, et al. Solid phase immunoadsorption for therapeutic and analytical studies on neuropathy-associated anti-GM1 antibodies. Glycobiology 2007;17:294-303. doi:10.1093/glycob/cwl074.

[16] Cabezas-Cruz A, Hodžić A, Román-Carrasco P, Mateos-Hernández L, Duscher GG, Sinha DK, et al. Environmental and molecular drivers of the $\alpha$-Gal syndrome. Front Immunol 2019;10:1210. doi:10.3389/ fimmu.2019.01210.

[17] de la Fuente J, Pacheco I, Villar M, Cabezas-Cruz A. The alpha-Gal syndrome: new insights into the tick-host conflict and cooperation. Parasit Vectors 2019;12:154. doi:10.1186/s13071-019-3413-z.

[18] Platts-Mills TA, Schuyler AJ, Tripathi A, Commins SP. Anaphylaxis to the carbohydrate side chain alpha-gal. Immunol Allergy Clin North Am 2015;35:247-260. doi:10.1016/j.iac.2015.01.009.

[19] Van Nunen S. Galactose-Alpha-1,3-Galactose, mammalian meat and anaphylaxis: A world-wide phenomenon? Curr Treat Options Allergy 2014;1:262-277. doi:10.1007/s40521-014-0022-0.

[20] Commins SP, Kelly LA, Rönmark E, James HR, Pochan SL, Peters EJ, et al. Galactose- $\alpha$-1,3-galactose-specific IgE is associated with anaphylaxis but not asthma. Am J Respir Crit Care Med 2012;185:723-730. doi:10.1164/rccm.201111-20170C.

[21] Galili U. Significance of the evolutionary $\alpha 1,3$-galactosyltransferase (GGTA1) gene inactivation in preventing extinction of apes and old world monkeys. J Mol Evol 2015;80:1-9. doi:10.1007/s00239-0149652-x.

[22] Soares MP, Yilmaz B. Microbiota control of malaria transmission. Trends Parasitol 2016;32:120-130. doi:10.1016/j.pt.2015.11.004.

[23] Cabezas-Cruz A, Mateos-Hernández L, Alberdi P, Villar M, Riveau G, Hermann $E$, et al. Effect of blood type on anti- $\alpha-G a l$ immunity and the incidence of infectious diseases. Exp Mol Med 2017;49:e301. doi:10.1038/emm.2016.164.

[24] Cabezas-Cruz A, Mateos-Hernández L, Pérez-Cruz M, Valdés J, Fernández de Mera IG, Villar M, et al. Regulation of the immune response to $\alpha$-gal and vector-borne diseases. Trends Parasitol 2015;31:470-476. doi:10.1016/j.pt.2015.06.016.

[25] Makkouk A, Weiner GJ. Cancer immunotherapy and breaking immune tolerance: new approaches to an old challenge. Cancer Res 2015;75:5-10. doi:10.1158/0008-5472.CAN-14-2538.

[26] Rodríguez Y, Rojas M, Pacheco Y, Acosta-Ampudia Y, Ramírez-Santana C, Monsalve DM, et al. Guillain-Barré_syndrome, transverse myelitis and infectious diseases. Cell Mol Immunol 2018;15:547-562. doi:10.1038/cmi.2017.142.

[27] Doncel-Pérez E, Mateos-Hernández L, Pareja E, García-Forcada A, Villar $\mathrm{M}$, Tobes $\mathrm{R}$, et al. Expression of early growth response gene-2 and regulated cytokines correlate with recovery from Guillain-Barré syndrome. J Immunol 2016;196:1102-1107. doi:10.4049/jimmunol.1502100.

[28] Mateos-Hernández L, Villar M, Doncel-Pérez E, Trevisan-Herraz $M$, García-Forcada A, Romero Ganuza F, et al. Quantitative proteomics reveals Piccolo as a candidate serological correlate of recovery from Guillain-Barré syndrome. Oncotarget 2016;7:74582-74591. doi:10.18632/oncotarget.12789.

[29] Mateos-Hernández L, Villar M, Moral A, García Rodríguez C, Alfaya Arias T, de la Osa, V, et al. Tick-host conflict: Immunoglobulin E antibodies to tick proteins in patients with anaphylaxis to tick bite. Oncotarget 2017;8:20630-20644. doi:10.18632/oncotarget.15243.

[30] Villar M, Mateos-Hernández L, de la Fuente J. The impact of postgenomics approaches in neurodegenerative demyelinating diseases: the case of Guillain-Barré syndrome. Current Med Chem 2018;25:3482-3490. doi:10.2174/0929867325666180314121813.

[31] Cabezas-Cruz A, de la Fuente J. Immunity to $\alpha$-Gal: the opportunity for malaria and tuberculosis control. Front Immunol 2017;8:1733. doi:10.3389/fimmu.2017.01733. 